\title{
Review - Recension
}

\section{TEACHING IS IMPORTANT. . .BUT TO WHOM?}

\section{A review of If Teaching is Important. . .The Evaluation of Instruction in Higher Education}

\author{
C.K. Knapper, G.L. Geis, C.E. Pascal, and B.M. Shore, editors. A CAUT Monograph. Toroto: \\ Clarke, Irwin and Company, Ltd. \$5.95, pp. $230 \& \mathrm{x}$ (with indices).
}

This volume is the second in a monograph series on problems encountered in Canadian universities. The first of these monographs, "but can you type?" (1977), is a documented account of the status of women in Canadian universities. Further volumes planned or in preparation will deal with such topics as university funding, Canadian universities and nationalism, and collective bargaining in universities.

The current volume contains eight topical chapters including one by each editor and a ninth titled "Conclusions" under the pen of all four editors. Chris Knapper is senior editor, having written an eight-page general introduction and one or one-and-a-half page introductions to each of the first eight chapters. Thus the browser is almost certain to encounter some of Knapper's prose, and the careful reader cannot avoid the stating and restating of his preferences on evaluating teaching. Geis and Shore are directly associated with the Centre for Learning and Development (C.L.D.) at McGill, Pascal recently left C.L.D. to assume a position at O.I.S.E., and Knapper (now at Waterloo) earned his Ph.D. at Regina and was head of Psychology there for some years immediately afterward.

We shall appraise each of the chapters and conclude with an overall "evaluation" of this work (meta-evaluation?). In order, the topical chapters are: 1. "Evaluation: Definitions, Problems and Strategies" (Geis); 2. "Student Learning and the Evaluation of Teaching" (Janet G. Donald, C.L.D.; and Shore); 3. "Student Evaluation of Instruction" (Gilles G. Nadeau, Moncton); 4. "A Framework for the Evaluation of Teaching" (Arthur M. Sullivan, Newfoundland); 5. "The Teacher and the Goals of the University" (Bernard Trotter, Council of Ontario Universities); 6. "Evaluating Academic Functions Outside the Classroom" (Pascal); 7. "Evaluation in Non-Academic Settings" (Paul A. Friesen, deceased); 8. "Teaching Evaluation and Academic Freedom" (Knapper).

If the documentation in but can you type? is a bit dated, the problem it discussed (the role of women in Canadian universities) certainly is not - a single contribution in If Teaching is Important. . .was co-authored by a woman! Dated documentation appears to be a chronic problem with this series as the references cited indicate a three-year lag between authorship and publication.

The first four chapters are clearly addressed to the heart of the matter; the second four are much more periferal; and the concluding piece seems a bit forced and clumsy (imagine four academics trying to write one chapter).

Geis' contribution will prove enlightening to those who regard academic evaluation too narrowly, either in purpose or in practice. He restates Scriven's now familiar (to educa: 
tionists) distinction between formative and summative evaluation and discusses formative evaluation in terms of nine reasons he believes teachers resist evaluation. He is quite correct in judging that few university teachers outside faculties of education make the formativesummative distinction in using the term "evaluation." Likewise, his cautiously positive approach to the topic seems to us to be useful and worthy of the attention of our colleagues in the several faculties.

Donald and Shore present a discussion of relationships between learning and teaching which again should enlighten those who think narrowly on these issues. The fallacy in considering that teaching quality is a primary determiner of student learning is clearly identified, for example. Explicitly influenced by Bloom and R.M. Gagné, Donald and Shore advance reasoned but optimistic advice to both faculty members and administrators.

Nadeau's piece on student evaluation of instruction is not only the longest (56 pages in the book), it is the most thorough of the set, and is easily the most satisfying to those professionally interested in staff improvement. This chapter is a comprehensive review of the burgeoning literature on this controversial topic up to early 1974.

As Knapper notes in the general introduction, much of the research in the area of this book has been done in the U.S.A. In fact, Donald and Shore cite over thirty authors, modestly omitting much of the McGill work, but including the work of only two British and two Canadian authors (not counting an inspirational quote from Leacock). The pity is that few U.S. academics and particularly investigators in this field are likely to read (or even hear about) a CAUT monograph containing such excellent reviews of their work.

Anyone who would adopt a position for or against student questionnaires would do well to read Nadeau's chapter carefully. Likewise, anyone who plans to use questionnaires or do research and development involving them could profit from his reasoned remarks.

Sullivan's chapter contains an interesting discussion of what he calls self-evaluation (roughly coterminus with formative evaluation), which of course he recommends for all, giving some good if largely common sense suggestions. Drawing upon his experiences as psychologist, chairman, and dean, and more recently principal, Sullivan goes on to discuss formal (summative) evaluation, recommending an annual performance review for all faculty. Although this may sound heavy-handed, the procedure recommended by Sullivan is fair and his general style illustrates a strong concern for morale and an optimistic, helpful approach to the matter.

Trotter discusses accountability and a teacher's role in the institution of the university as well as in an academic discipline. The chapter dovetails nicely with the following one by Pascal, if not so much with the title or purpose of the volume. The fact that teaching takes place in a variety of modes and settings apart from lecturing in a classroom is emphasized in both chapters. Trotter is more realistic and explicit about relations between the university community and the rest of society than the other authors, and he does it in an economy of space (8 pages). Somehow this chapter, nontheless, does not seem essential to the general flow of the volume. This is probably because he is explicitly concerned more with matters of institutional loyalty than with the facilitation of classroom learning.

Pascal's chapter at first seems to dwell upon the obvious, listing the many categories of academic activity undertaken by modern faculty members. If the reader were not closely affiliated with a university, however, it might not be all that obvious, and it is nice to be reminded of the legitimacy of one's contributions outside the classroom anyway. A few 
months ago the Christian Science Monitor published a type of article most newspapers unfortunately eschew: a day in the life of an English professor. The sheer volume of his teaching, counseling, research, and administrative responsibilities was staggering. More than a few columists across Canada could broaden their perspectives on university life from the insights in that article or in Pascal's chapter.

The editors' reasons for the inclusion of Friesen's posthumously published article are a bit enigmatic. The point of view is purportedly that of an interested, intelligent layman, highlighting for the reader the contrast between university education and non-academic training programs in business and industry. Friesen would explain academe to those in business and vice versa. A worthy goal except that the former are unlikely to ever see this volume and the latter are most likely to skip this chapter.

Knapper's article, citing his own work for CAUT, returns to one of his favourite themes, unabashed negativism about the value of student questionnaires. This position, which emerges a number of times in the various introductions, this time is stated from the standpoint of a "traditional concept of academic freedom." His arguments and asides will be of use and comfort to those who oppose student questionnaires for whatever reason. Knapper is so firm in his convictions about their shortcomings, the reader might suppose that his mother was frightened by a student questionnaire when he was yet in utero. More likely, like most of us, he probably received some bad results from a questionnaire one day and has experienced difficulty recovering. A position Knapper published in the CAUT Bulletin some years back expressing doubts about the likelihood that faculties of education could spawn or manage campus-wide teaching improvement activities is mercifully neither restated nor unfortunately recanted here.

The negative stance of Chapter 8 carries over into the concluding piece, which includes a criticism of Nadeau's interpretation of consistency in student ratings while generally praising those of the other contributors. The conclusion contains a call for a moratorium on summative use of student questionnaire data because of potential misuse and the gap between research and practice. A recent review of the research literature on instructional psychology by Wittrock and Lumsdaine (Annual Review of Psychology, 1977) contains reservations about summative use of student questionnaires but finds them clearly defensible for formative purposes. The editors should have preserved the original emphasis on the formative and drawn the distinction between these two uses of evaluation more clearly in their conclusions, perhaps setting them down in parallel sections. Nadeau, Geis, and Sullivan and the CAUT Guidelines (co-authored by Knapper) call for very careful use of student questionnaire data, not a moratorium (for research and development to catch up with practice and to avoid misuses and abuses). The other conclusions advanced in Chapter 9 seem largely sound, but any moratorium on questionnaires runs contrary to widespread practice. We may as well suspend classes until philosophers have satisfactorily defined "teaching."

Among the problems with this volume as a whole is that it almost ceases to be a monograph, given the diversity of some of the contributions. Friesen's and Trotter's chapters were included with a view toward selling the book to a wider readership than academics. Indeed, the general editor's (Naomi Griffiths) preface states that an attempt was made to appeal to "the popular market." Perhaps that justifies her use of that odious (to many academics) word "business" to describe higher education twice at the outset of the preface. 
Indeed, a strong case can be made that there is a need for increased communication and mutual understanding between the general public and the academic community. It is doubtful, however, that this volume or series will (or could) contribute very much to satisfy that need. As suggested above, a series in the popular press might be indicated if the public universities are to "go public." If economic viability were an issue, the editors should have opted for contributions addressed to academics throughout the English speaking world. Admittedly, that seems to be tangent to CAUT's purposes, but, as mentioned above, the analyses of work done elsewhere are potentially helpful beyond Canada's borders. it should be noted that important work done in central and western Canada (notable at the University of Manitoba and to an extent at Simon Fraser and U.B.C.) are not treated in this yolume. Nor is the work of the London and Lancaster groups and their offshoots at Exeter and Bradford (except for abrief citation of Ruth Beard's book), nor the work done in New South Wales or Melbourne, Australia, cited. It should have been, since Knapper held a grant to visit these centres a few years ago to study their work. Again, the reader may have been victimized by an intolerably long publication lag. Chapters on self-evaluation and on peer evaluation to parallel Nadeau's on student evaluation should certainly have been included. Likewise, recent developments at McGill, for example development of the Instructional Analysis Kit, should have been included.

Whereas Sheffield's Teaching in the Universities: No One Way (McGill-Queens, 1974) served as inspiring reading, the contents of the Knapper et al. volume give more detailed direction to that inspiration and guidelines for evaluating the results. In a sense, however, the whole comes out to total less than the sum of its parts. Cohesion is, of course, a common problem with anthologies. An editorship contributing more than one half of the total content plus invited authorship of contributions ought to go some way to resolving the cohesiveness problem. In this case it did not.

We do sincerely hope that Nadeau's chapter will receive the attention that it deserves and likewise certain others, in particular the sections by Geis, Donald and Shore, Sullivan, and Pascal.

Parts of this work stand alone as contributions to the literature on teaching evaluation in higher education. The authors and editors should be pleased at this accomplishment. These parts cause the reviewers to lament that a wider academic and administrative readership within and without Canada might not be reached. The most diverse sections are mercifully short and thus do not detract that much from the general impact of the work, which we judge to be good. The senior editor, despite his bias against student questionnaires, does a good job of tying the chapters together and providing an "advance organizer" to each one. This volume ranks with the Sheffield work cited above as an important statement about teaching in Canadian universities in this decade. Hopefully there will be others.

\author{
Stephen F. Foster \\ J. Gordon Nelson \\ Faculty of Education \\ The University of British Columbia
}

